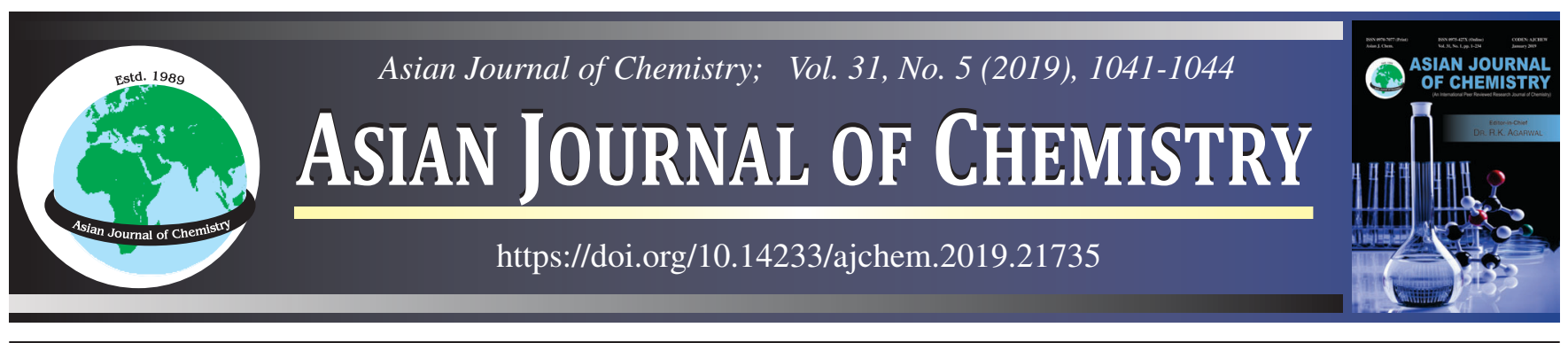

\title{
Synthesis, Electronic Spectral Study and Antifungal Evaluation of Mixed Ligand Complexes of Dibasic Tridentate Schiff Base and Naphthoic Acid with Transition Metal Ions
}

\author{
Mukti Verma $^{1}$, Moni Verma ${ }^{2}$ and Nazia Tarannum ${ }^{1, *}$ \\ ${ }^{1}$ Department of Chemistry, Chaudhary Charan Singh University, Meerut-250005, India \\ ${ }^{2}$ Department of Chemistry, Nanak Chand Anglo Sanskrit College, Meerut-250003, India \\ *Corresponding author: E-mail: naz1012@gmail.com \\ Received: 1 October 2018; \\ Accepted: 14 December 2018; \\ Published online: 28 March 2019; \\ AJC-19327 \\ Transition metal complexes of $\mathrm{Mn}(\mathrm{II}), \mathrm{Co}(\mathrm{II})$ and $\mathrm{Cu}(\mathrm{II})$ with dibasic tridentate Schiff base derived from the condensation of thiosemi-
carbazide with acetoacetanilide as primary ligand and 1-hydroxy-2-naphthoic acid as co-ligand have been synthesized. The mixed ligand
complexes of the above mentioned metal ions were characterized by analytical, magnetic and electronic spectral study. The transition
metal complexes were also evaluated for antifungal activity against Drechslera tetramera, Fusarium oxysporum and Aternaria alternata
at different concentrations. \\ Keywords: Transition metals, Tridentate Schiff base, Mixed ligand, Naphthoic acid, Antifungal activity.

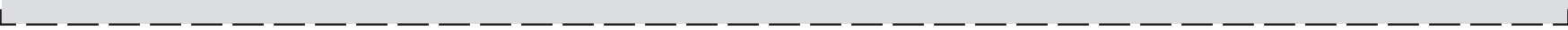

\section{INTRODUCTION}

The coordination chemistry of transition metals and their derivatives has gained much importance because of their biological importance [1-3]. The metal thiosemicarbazone compounds are emerging as a new class of experimental anticancer chemotherapeutic agents [4], which shows inhibitory activity against most of the cancers through inhibition of a crucial enzyme obligatory for DNA biosynthesis and cell division $[5,6]$. The complexes of magnese play an important role in photochemical reactions [7]. Nitrogen, oxygen and sulphur donor ligands possess a range of biological applications such as antitumour [8], antiviral [9], antibacterial [10], antimalarial [11] and antifungal activities [12]. Mixed ligand complexes of transition metals containing ligands with $\mathrm{N}, \mathrm{S}$ and $\mathrm{N}, \mathrm{S}, \mathrm{O}$ donors are known to show interesting stereo-chemical, electrochemical and electronic properties [13-15].

Schiff bases derived from a large number of carbonyl compounds and amines have been used in coordination chemistry. The metal complexes of 2-amino-4-phenyl-5-arylazothiazole and salicylaldehyde are reported earlier. Recently, the importance of mixed ligand complexes in medicinal [16], analytical [17] and industrial chemistry [18] has led to a large number of reports in the formation of stabilities of mixed ligand comp- lexes [19]. The role of mixed ligand complexes in the biological process has been well recognized [20]. Some scattered references [21-25] are available on metal complexes of biologically active ligands. The survey of the literature revealed that no work seems to be done so far on the mixed ligands complexes containing dibasic tridentate Schiff bases as primary and naphthoic acid as co-ligands. So it is worthwhile to prepare transition metal complexes of Schiff base as primary and naphthoic acid as co-ligand and study their structural and biological activity. The present paper deals with the preparation and characterization of $\mathrm{Co}$ (II), $\mathrm{Mn}$ (II) and $\mathrm{Cu}$ (II) metal ion complexes with dibasic tridentate Schiff base derived by the condensation of thiosemicarbazides with acetoacetanilide as primary ligand and 1-hydroxy-2-naphthoic acid as co-ligand. Mixed ligand complexes of the above mentioned metal ions were prepared and characterized on the basis of their analytical and electronic study. The transition metal complexes were evaluated for their antifungal activity as well.

\section{EXPERIMENTAL}

All the chemicals used were of chemically pure analytical grade. The solvent were dried and distilled before use Metal(II) chloride, thiosemicarbazide, acetoacetanilide, $o$-chloro aceto-

This is an open access journal, and articles are distributed under the terms of the Creative Commons Attribution-NonCommercial-ShareAlike 4.0 (CC BY-NC-SA 4.0) International License which allows readers to freely read, download, copy, distribute, print, search, or link to the full texts of its articles and to use them for any other lawful non-commercial purpose as long as the original source is duly acknowledged. 
acetanilide, 1-hydroxy-2-naphthoic acid and 3-hydroxy-2naphthoic acid were procured from Fischer Scientific, India. Dimethyl formamide (DMF) and alcohol were purchased from Fischer Scientific, India.

The elemental analysis was performed at Central Drug Research Institute, India. Conductance of metal complexes was measured in nitromethane at $25{ }^{\circ} \mathrm{C}$ on Toshniwal conductivity bridge CL01/01 using dip type cell. The following accepted range of molar conductivity for water at concentration equal to $\mathrm{M} / 1000$ and temperature $25{ }^{\circ} \mathrm{C}$ was taken to determine the number of ions present in solution. The standard range of molar conductivity in mhos of uni-divalent electrolyte is 215-273 mhos. Infrared spectra of the ligands and their metal complexes were recorded on Beckmann IR 120 Spectrophotometer and Perkin Elmer improved 137 spectrophotometer in Nujol mull and $\mathrm{KBr}$ in the range 200 to $400 \mathrm{~cm}^{-1}$ and 400$4000 \mathrm{~cm}^{-1}$ at room temperature. The electronic spectra of the complexes were recorded in ethanol at room temperature on CZ-specord UV-vis-spectrophotometer provided with an automatic recorder. The magnetic succeptibility at room temperature was determined on Gouy's electromagnetic balance and corrected for dimagnetism.

Preparation of primary ligand (Schiff base): The ligand was prepared by the condensation of thiosemicarbazide with acetoacetanilide in 1:1 molar ratio. The reaction mixture was refluxed for $6 \mathrm{~h}$ on water bath. The resulting mixture was then allowed to cool. The solid precipitate separated out was filtered by suction and dried in vacuum.

Preparation of mixed ligand complexes: The desired mixed ligand complexes were prepared from solution of metal salts $(\mathrm{Mn}, \mathrm{Cu}$ and $\mathrm{Co}$ ) in ethanol and primary ligand prepared as above and then adding to it ethanolic solution of secondary ligand i.e. 1-hydroxy-2-naphthoic acid. The mixed solution of both ligands and metal salts were refluxed on water bath for $8 \mathrm{~h}$ to get the complex, $\mathrm{pH}$ was maintained between 3-4 by addition of acid. The newly synthesized complexes were filtered and dried in vacuum over anhydrous calcium chloride.

Antifungal activity: The fungicidal activity of ligand as well as their metal complexes were determined using the growth method [25]. The activity was determined against various fungi i.e. Drechslera tetramera, Fusarium oxysporum and Aternaria alternata at different concentrations. The testing samples were incorporated in warm Czapeck's Dox agar medium at different concentrations viz. 100, 200, $500 \mathrm{ppm}$. The test samples and the medium were autoclaved at $15 \mathrm{lbs}$ for $15 \mathrm{~min}$ and then shaken well to give uniform dispersal of the chemical. The samples were poured into sterilized petridish keeping three replications of each treatments and a check without chemicals. Then the plates were inoculated centrally with a mycelia disc from 7 days old culture of the fungi towards complexes. The linear mycelia growth rates in the presence of test samples and untreated controls was carried out and the data was statistically analyzed according to the following formula:

$$
\text { Inhibition }(\%)=\frac{\mathrm{C}-\mathrm{T}}{\mathrm{C}} \times 100
$$

where $\mathrm{C}=$ diameter of fungus colony in control plates after $96 \mathrm{~h}, \mathrm{~T}=$ diameter of fungus colony in treated plates after $96 \mathrm{~h}$.

\section{RESULTS AND DISCUSSION}

The elemental analysis of the above complexes shows the formation of 1:1:1 (metal:primary ligand:secondary ligand) complexes in all the cases. All the complexes are coloured and quite stable in air and light. The analytical data given in table for the complexes are in good agreement with the formula proposed.

Infrared spectral studies: The infrared and far infrared spectra of the ligand and its complexes were recorded to detect the coordination. The spectra of the free ligands when compared with the complexes show the coordination of thiosemicarbazones and naphthoic acid to the metal ions. The spectra of the free ligands show two bands around 3450 and 3300 $\mathrm{cm}^{-1}$ due to $v_{\text {as }}$ and $v_{\text {sym }}$ of terminal $\mathrm{NH}_{2}$ group [26]. These bands remain practically unaltered in the corresponding metal complexes showing the non-involvement of this group on complexation. The absorption due to $v(\mathrm{C}=\mathrm{N})$ of the free ligand appearing in the region $1620 \mathrm{~cm}^{-1}$ undergoes a negative shift for $5-20 \mathrm{~cm}^{-1}$ in the spectra of the metal complexes indicating the coordination of azomethine nitrogen to the metal [13]. The bands of strong intensities in the spectra of the ligand around $1660 \mathrm{~cm}^{-1}$ are due to $v(\mathrm{C}=\mathrm{O})$. In the spectra of complexes, this has disappeared and formation of a new band appeared around $1620 \mathrm{~cm}^{-1}$, which can be attributed to the enolization and subsequent coordination through the deprotonated oxygen atom of the $-\mathrm{CH}_{2}-\mathrm{C}=\mathrm{O}$ group [27]. The band due to $v(\mathrm{C}=\mathrm{S})$ appeared around $830 \mathrm{~cm}^{-1}$ in the free ligand disappears on complexation and a new band appeared around $720-760 \mathrm{~cm}^{-1}$. These observations may be concluded to thioenolization of $\mathrm{NH}-\mathrm{C}=\mathrm{S}$ group and subsequent coordination through the deprotonated sulphur [28]. Thus, it can be concluded that thiosemicarbazones is potentially dibasic tridentate ligand and the coordination sites are $\beta$-nitrogen and thiolato sulphur and oxygen after deprotonation. The possibility of $\alpha$-nitrogen coordination is ruled out because of considerable strain [29].

Magnetic moment and electronic spectral studies: Correlations of the magnetic and spectral properties of transition metal complexes derived from nitrogen and oxygen donor atom ligand has been reported herein.

Manganese(II) complex: Mn(II) ion in a weak octahedral field may show paramagnetism corresponding to five unpaired electrons having magnetic moment 5.92 B.M. with the ground state $\left(\mathrm{t}_{2 \mathrm{~g}}\right)^{3}(\mathrm{eg})^{2}$. In the strong ligand field, it assumes $\left(\mathrm{t}_{2 \mathrm{~g}}\right)^{5}$ configuration where the strong field ligands may force two of the spins to pair leaving only one unpaired electron, hence such compounds exhibit magnetic moment of 2.5 B.M., a little larger than the spin only value for one unpaired electron. Since Mn(II) ion has $d^{\tilde{b}}$ configuration, it is capable of forming spin free as well as spin paired complexes. Due to additional stability of half-filled $d$-shell, spin free complexes are most predominant. Since spin free $\mathrm{Mn}(\mathrm{II})$ complexes have orbitally nondegenerate ${ }^{6} \mathrm{~S}$ ground term, spin only magnetic moments of 5.92 B.M. is however, expected which will be independent of temperature and stereochemistry. In present study, the complex shows magnetic moment in the range 5.85 B.M sugges-ting, thereby, that it is spin free octahedral complex having five unpaired electrons. The absorption bands in the spectra correspond to the spin forbidden transition from the ground state $\left({ }^{6} \mathrm{~A}_{1}\right)$ to the levels arising from ${ }^{4} \mathrm{G},{ }^{4} \mathrm{P}$ and ${ }^{4} \mathrm{D}$ excited 
states of the free ion. Further, three absorption bands due to transitions to the levels arising from ${ }^{4} \mathrm{~F}$ state will occur in UV region. The energies of ${ }^{6} \mathrm{~A},{ }^{4} \mathrm{E}\left({ }^{4} \mathrm{D}\right)$ and ${ }^{4} \mathrm{E}(\mathrm{G}),{ }^{4} \mathrm{~A}\left({ }^{4} \mathrm{G}\right)$ states are independent of $10 \mathrm{Dq}$ and depends only on $\mathrm{B}$ and $\mathrm{C}$.

The colour of the complex is light pale-pink with melting point of $167^{\circ} \mathrm{C}$. However, the intensity of electronic transitions from the ground state to the state of four-fold multiplicity is quite weak. The complex displays three absorption bands at 18550,22300 and $28060 \mathrm{~cm}^{-1}$ assigned to sextet quartet transitions ${ }^{6} \mathrm{~A}_{1 \mathrm{~g}} \rightarrow{ }^{4} \mathrm{~T}_{1 \mathrm{~g}}\left({ }^{4} \mathrm{G}\right)\left(v_{1}\right),{ }^{6} \mathrm{~A}_{\mathrm{lg}} \rightarrow{ }^{4} \mathrm{Eg}\left({ }^{4} \mathrm{D}\right)\left(v_{2}\right)$ and ${ }^{6} \mathrm{~A}_{1 \mathrm{~g}}$ $\rightarrow{ }^{4} \mathrm{~T}_{1 \mathrm{~g}}\left({ }^{4} \mathrm{P}\right)\left(\mathrm{v}_{3}\right)$, respectively. The values of Dq, B and $\mathrm{C}$ have been computed using the equation suggested by Figgis and the values are 1850,750 and $3000 \mathrm{~cm}^{-1}$, respectively.

Cobalt(II) complex: The magnetic moment of different types of $\mathrm{Co}$ (II) complexes lie in the range (i) 2.1-2.9 B.M. for square planar and (ii) 4.2-4.8 B.M. for high spin five coordinated complexes. The observed magnetic moment for $\mathrm{Co}$ (II) complex is 4.67 B.M which is used as a criteria to determine the type of geometry around the metal ion. The colour of the complex is violet with melting point $260^{\circ} \mathrm{C}$. This value suggest an octahedral geometry for $\mathrm{Co}$ (II) complex [30]. The electronic spectra of Co(II) complex shows two band at 17860 and 18520 $\mathrm{cm}^{-1}$. These two bands are assigned to ${ }^{4} \mathrm{~T}_{1 \mathrm{~g}}(\mathrm{~F}) \rightarrow{ }^{4} \mathrm{~A}_{2 \mathrm{~g}}(\mathrm{~F})\left(\mathrm{v}_{2}\right)$ and ${ }^{4} \mathrm{~T}_{\mathrm{gg}}(\mathrm{F}) \rightarrow{ }^{4} \mathrm{~T}_{2 \mathrm{~g}}(\mathrm{~F})\left(v_{3}\right)$ transitions respectively in an octahedral environment [31]. The band $v_{1}$ may not be observed due to the limited range of the instrument. However, $v_{1}$ would be calculated using band filling procedure [32]. The octahedral geometry [33] is further supported by the values of ligand field parameters like Dq, $\beta^{\prime}, \beta$ which are found as 949,824 and 0.85 , respectively.

Copper(II) complex: The curpric ion has $3 d^{9}$ configuration having one unpaired electron. Its complex usually have simple square planar to tetragonally distorted octahedral stereochemistry. However, irrespective of the stereochemistry involved, the magnetic moment has been found to be (with spin-orbit coupling constant of $850 \mathrm{~cm}^{-1}$ ) about 1.92 B.M. Generally, octahedrally coordinated $\mathrm{Cu}$ (II) complexes have magnetic moments in the range of 1.90-2.20 B.M. and the values are independent of temperature. The effective magnetic moment value for $\mathrm{Cu}$ (II) complex is $1.92 \mathrm{~B}$.M. suggesting the distorted octahedral geometry. Copper(II) complex shows broad asymmetric band at $16390 \mathrm{~cm}^{-1}$. The broadness of the band may be due to dynamics John-Teller distortion. The observation suggests that the complex has distorted octahedral structure. $\mathrm{D}_{\mathrm{q}}$ value was found to be 1538 . The complex colour is green with melting point $287^{\circ} \mathrm{C}$.

Antifungal activity: The life processes of organism are controlled and directed by a complex and inter related series of enzymes system. It is however, believed that the metal complexes may penetrate the wall or lipoid membrane in the form of simple chelates, inhibiting specific enzymes causing toxic reactions among cellular constituents and ultimately causing death of the organism. The idea that fungitoxicants react mainly with ligands on conidial surfaces and are primarily accumulated on the surface does not have valid experimental support. However, the migration of fungicides to the sites of action consist of a complicated series of reactions that involve both the electronic and hydrophobic nature of the toxicants. The bound metal mostly attacks the functional groups contained in the living tissues. The functional groups most frequently attached are thiol and amino groups. Certain metals like $\mathrm{Cu}(\mathrm{II})$ is known to exert a striking influence in the sporulation of fungi, however, different fungi seem to differ in their responses.

Role of Mn(II) has been noted in the biosynthesis of some primary and secondary fungal metabolites also. The data on colony growth responses of Drechslera tetramera, Alternaria alternata and Fusaricum oxysporum at different concentrations of 500, 200 and $100 \mathrm{ppm}$ using three replications in each case are recorded in Table-1. The analysis of the fungicidal result showed a definite pattern existing between fungi toxicity and chemical structure. The results indicate that in untreated control the test fungi grew, whereas the growth of fungi is inhibited well by all the complexes. It may be concluded that the ligand possess good fungicidal activity against all the three fungi.

It is evident that among all the metal complexes tested for their antifungal activity, $\mathrm{Cu}$ (II) complex is most active fungicide. The fungicidal action of $\mathrm{Cu}$ (II) complex may be explained due to inactivation of enzymes. The other metal complexes are however not much fungi toxic for the particular fungi. Generally, fungi toxicity is enhanced with increase in the dose of complex. However, a correlation between toxicity of metals and their ability to form stable metal chelates revealed the following order $\mathrm{Cu}$ (II) $>\mathrm{Co}$ (II) $>\mathrm{Mn}$ (II).

\section{Conclusion}

In the present work, three mixed ligand complexes of $\mathrm{Mn}$ (II), $\mathrm{Co}(\mathrm{II})$ and $\mathrm{Cu}$ (II) have been successfully synthesized along with tridentate Schiff base derived by condensation of thiosemicarbazides with acetoacetanilide as primary ligand and 1-naphthoic acid as co-ligand. The transition metal complexes were characterized by FTIR, elemental analysis and electronic spectral study. The antifugal activity of the three compounds were performed with fungi Drechslera tetramera, Alternaria alternate and Fusarium oxysporum at different concentrations. The growth response and average $\%$ inhibition after $46 \mathrm{~h}$ of

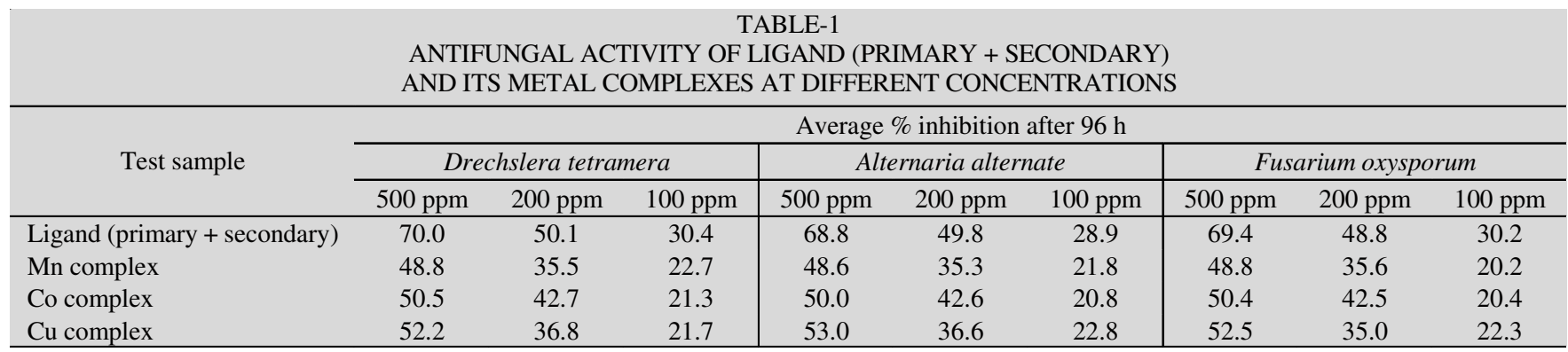


exposure to fungi strain was observed in relation to the ligand and its metal complexes. The study confirmed that $\mathrm{Cu}$ (II) is the most active fungicide followed by $\mathrm{Co}$ (II) and then $\mathrm{Mn}$ (II) respectively. The observed magnetic moment for $\mathrm{Mn}$ (II), $\mathrm{Co}$ (II) and $\mathrm{Cu}(\mathrm{II})$ are 5.85, 4.67 and 1.92 B.M., respectively and the predicted geometry for the compounds are spin free octahedral, octahedral and distorted octahedral.

\section{CONFLICT OF INTEREST}

The authors declare that there is no conflict of interests regarding the publication of this article.

\section{REFERENCES}

1. K.L. Haas and K.J. Franz, Chem Rev., 109, 4921 (2009); https://doi.org/10.1021/cr900134a.

2. A. Bansal and R.V. Singh, Synth. React. Inorg. Met.-Org. Chem., 31, 381 (2001); https://doi.org/10.1081/SIM-100002226.

3. S. Guo, E. Ding, H. Chen, Y. Yin and X. Li, Polyhedron, 18, 735 (1999); https://doi.org/10.1016/S0277-5387(98)00347-7.

4. J. Patole, S. Padhye, C.J. Newton, C. Anson and A.K. Powell, Indian J. Chem., 43A, 1654 (2004); https://www.researchgate.net/publication/297577821.

5. A. Murugkar, B. Unnikrishnan, S. Padhye, R. Bhonde, E. Triantafillou, S. Teat and E. Sinn, Met. Based Drugs, 6, 177 (1999); https://doi.org/10.1155/MBD.1999.177.

6. A. Murugkar, S. Padhye, S. Guha-Roy and U. Wagh, Inorg. Chem. Commun., 2, 545 (1999); https://doi.org/10.1016/S1387-7003(99)00152-5.

7. H.T. Zhang and T.L.Brown, J. Am. Chem. Soc., 115, 107 (1993); https://pubs.acs.org/doi/pdf/10.1021/ja00054a016.

8. S.K.S. Gupta, O.P. Pandey, A. Bhatt, V. Srivastava and K.N. Mishra, Indian J. Chem., 41A, 1421 (2002).

9. K.M. Ibrahim, S.I. Mostafa, N. Nawar and Z.A. Younis, Indian J. Chem., 43A, 2294 (2004).

10. R.C. Maurya, A. Pandey and D. Sutradhar, Indian J. Chem., 43A, 763 (2004).

11. S. Dave, A. Chaudhary, M. Agrawal, S.C. Joshi and R.V. Singh, Indian J. Chem., 42A, 268 (2003).

12. K. Dey, B. Bikash and S.Sarkar, Indian J. Chem., 43A, 773 (2004).

13. R. Prabhakaran, A. Geetha, M. Thilagavathi, R. Karvembu, V. Krishnan, H. Bertagnolli and K. Natarajan, J. Inorg. Biochem., 98, 2131 (2004); https://doi.org/10.1016/j.jinorgbio.2004.09.020.
14. S. Dhar, M. Nethaji and A.R. Chakravarty, Inorg. Chem. Acta, 358, 2437 (2005); https://doi.org/10.1016/j.ica.2005.02.006.

15. N. Bharti, Shailendra, S. Sharma, F. Naqvi and A. Azam, Bioorg. Med. Chem., 11, 2923 (2003); https://doi.org/10.1016/S0968-0896(03)00213-X.

16. S.L. Nalanda, M.C. Ganoukar and R.N. Rama, J. Indian Chem. Soc., 72 , 739 (1997).

17. J. Chakraborty and R.N. Patel, J. Indian Chem. Soc., 73, 19 (1996).

18. P. Chattopadhyay, B.K. Dolui and C. Sinha, Indian J. Chem., 36A, 419 (1997).

19. J.K. Nag, D. Das, C. Sinha and B.B. De, J. Indian Chem. Soc., 75, 496 (1998).

20. A. Kriza, C. Spinu and M. Pleniceanu, J. Indian Chem. Soc., 77, 83 (2000).

21. I. Kubo, K. Nihei and K. Shimizu, Bioorg. Med. Chem., 12, 5343 (2004); https://doi.org/10.1016/j.bmc.2004.07.050.

22. T. Aiyelabola, E. Akinkunmi, E. Obuotor, I. Olawuni, D. Isabirye and J. Jordaan, Bioinorg. Chem. Appl., 2017, Article ID 6426747 (2017); https://doi.org/10.1155/2017/6426747.

23. J. Kang, L. Zhuo, X. Lu, H. Liu, M. Zhang and H. Wu, J. Inorg. Biochem., 98, 79 (2004); https://doi.org/10.1016/j.jinorgbio.2003.08.015.

24. A. Atoui, Food Chem., 89, 27 (2005); https://doi.org/10.1016/j.foodchem.2004.01.075.

25. A.M. Oliveira-Brett and V.C. Diculescu, Bioelectrochemistry, 64, 143 (2004); https://doi.org/10.1016/j.bioelechem.2004.05.002.

26. D.M. Boghaei and S. Mohebi, J. Mol. Catal. Chem., 179, 41 (2002); https://doi.org/10.1016/S1381-1169(01)00330-2.

27. R. Raveendran and S. Pal, Polyhedren, 24, 57 (2005); https://doi.org/10.1016/j.poly.2004.09.027.

28. S.K. Dutta, D.B. McConville, W.J. Youngs and M. Chaudhury, Inorg. Chem., 36, 2517 (1997); https://doi.org/10.1021/ic960670z.

29. M. Akbar Ali and S.E. Livingstone, Coord. Chem. Rev., 13, 101 (1974); https://doi.org/10.1016/S0010-8545(00)80253-2.

30. B.N. Figgis and J. Lewis, ed.: F.A. Cotton, Progress in Inorganic Chemistry, Interscience: New York (1967).

31. A.B.P. Lever, Inorganic Electronic Spectroscopy, Elsevier: Amsterdam edn 2 (1984).

32. A.E. Underhill and D.E. Billing, Nature, 210, 834 (1966); https://doi.org/10.1038/210834a0.

33. A.P. Mishra and S.K. Gautam, J. Indian Chem. Soc., 81, 324 (2004). 